\title{
Nuclear microRNAs in normal hemopoiesis and cancer
}

John E.J. Rasko ${ }^{1,2,3}$ and Justin J.-L. Wong ${ }^{1,2,4,5^{*}}$

\begin{abstract}
Since the discovery of microRNAs (miRNAs) in the early 1990s, these small molecules have been increasingly recognized as key players in the regulation of critical biological processes. They have also been implicated in many diverse human diseases. The canonical function of miRNAs is to target the $3^{\prime}$ untranslated region (3' UTR) of cytoplasmic messenger RNA to post-transcriptionally regulate mRNA and protein levels. It has now been shown that miRNAs can also bind to the promoter regions of genes or primary miRNA transcripts to regulate gene expression. Such observations have indicated the presence of miRNAs in the nucleus and implied additional noncanonical functions. Nevertheless, the role(s) of nuclear miRNAs in normal hemopoiesis and cancer remains elusive despite a burgeoning literature. Herein, we review current knowledge concerning the abundance and/or functions of nuclear miRNAs during blood cell development and cancer biology. We also discuss ongoing challenges in order to provoke further studies into identifying key roles for nuclear miRNAs in the development of other cell lineages and human cancers.
\end{abstract}

Keywords: miRNAs, Hemopoiesis, Cancer, Gene regulation, Nuclear localization, Blood

\section{Background}

Non-coding RNAs are RNA molecules that are not translated into proteins but are nevertheless functional. They include long non-coding RNAs, intronic RNAs, circular RNAs, competing endogenous RNAs, microRNAs (miRNAs) and Piwi-interacting RNAs that are known to regulate gene expression at both the transcriptional and post-transcriptional levels [1-5]. Of all noncoding RNA species, miRNAs are best characterized in terms of their biogenesis and functions.

miRNAs are approximately 22 nucleotides in length. They play major roles in numerous biological processes including cell differentiation, lineage specification, reprogramming, immune response and the cell cycle [6-10]. Almost 30,000 miRNAs in 223 animal and plant species have been annotated in the miRNA database, miRBase (Release 21, June 2014). Even viruses, particularly herpesviruses, encode miRNAs to enhance their replication potential $[11,12]$. The biological importance of miRNAs

\footnotetext{
*Correspondence: j.wong@centenary.org.au

${ }^{1}$ Gene \& Stem Cell Therapy Program, Centenary Institute, University of Sydney, Camperdown 2050, Australia

'Sydney Medical School, University of Sydney, Camperdown, NSW 2050,

Australia

Full list of author information is available at the end of the article
}

is further highlighted by the deregulation of miRNA expression in many diverse human diseases including cardiovascular [13], neuronal [14, 15], inflammatory [15], dermatological [16], hepatological [17] and malignant diseases [18-20]. Given their key roles in many normal and disease-related processes, it is not surprising that miRNAs are enthusiastically viewed as potential druggable targets. To achieve this goal and anticipate side effects, it is important to understand their mechanisms of action and functions.

It is generally recognized that most mature miRNAs are localized in the cytoplasm along with the four catalytic Argonaute (Ago) proteins, where they contribute to the RNA-induced silencing complex (RISC) [21-23]. It is via this RISC complex that miRNAs regulate gene expression by targeting messenger RNAs (mRNAs). The majority of binding sites for miRNAs are within the 3' untranslated region ( $3^{\prime}$ UTR) of target mRNAs in animals, whereas they are often within coding regions in plants [24]. A mature miRNA can bind to the 3' UTR of a target mRNA based on partial sequence complementarity between the two to initiate one of several mechanisms to reduce mRNA and/or protein levels. These mechanisms include repression of translational elongation, impairment of translation initiation, 
and decapping and deadenylation of mRNA, which are reviewed extensively elsewhere [25-27].

Notably, numerous nuclear miRNAs have also been reported. These miRNAs may have diverse known or unknown non-canonical functions. Herein, we discuss how nuclear-localized miRNAs, although synthesized through biogenesis pathways identical to cytoplasmic miRNAs, could be shuttled back and retained in the nucleus to exert functions that differ from canonical miRNA actions. We focus especially on our current knowledge concerning the distribution and roles of these miRNAs in hemopoietic and cancer cells.

\section{Evidence of nuclear-localized miRNAs}

Systematic profiling analyses performed on nuclear and cytoplasmic-fractionated RNA samples have concluded that the majority of miRNAs are present in the nucleus $[28,29]$. These results indicate that most, if not all, miRNAs have the capacity to shuttle between the nucleus and cytoplasm. This finding is supported by the localization of Ago proteins in the nucleus and a recent discovery that a component of the RISC complexes, TNRC6A, is a nuclear and cytoplasmic shuttling protein that facilitates Ago nuclear transport. [30, 31] In vitro knockdown of Importin 1 and 8 has also been shown to reduce the nuclear localization of Ago proteins and/or miRNAs, indicating that these transporter proteins mediate the translocation of Ago/miRNAs into the nucleus (see reviews by Liang et al. [32] and Roberts [33], for details) [32, 33].

In addition to nuclear import mechanisms, there are also miRNA-intrinsic aspects that facilitate nuclear localization. The first evidence was provided by the predominant localization of miR-29b in the nuclei of HeLa and NIH3T3 cells, as directed by a hexanucleotide motif (AGUGUU) at its $3^{\prime}$ terminus [34]. A related miRNA, miR-29a, lacked this hexanucleotide motif and is enriched in the cytoplasm [34]. Notably, a synthetic siRNA harboring the miR-29a sequence engineered to include the AGUGUU motif could be directed into the nucleus, indicating the importance of this motif for nuclear localization [34]. Hwang and co-workers further identified variants of this motif that is associated with the nuclear localization of miRNAs, including UGUGUU, ACUGUU, AGAGUU, AGUCUU, AGUGAU, AGUGUA, AGNGUN [35]. An independent study by Jeffries and co-workers confirmed the presence of these motifs in seven other nuclear-localized miRNAs: miR30b, miR-30c, miR-19a, miR-374a, miR-374b, miR-590$5 \mathrm{p}$ and miR-193b [36].

However, these motifs alone may not be sufficient to direct nuclear localization of miRNAs [28]. For example, miR-92b that possesses a hexanucleotide motif identical to the nuclear-localized miR-29b has been reported to be cytoplasmically enriched [28]. A recent study also failed to identify a relationship between nuclear or cytoplasmic enrichment of miRNAs and their seed sequences, suggesting that seed identity itself is insufficient to determine their predominant localization [36]. As yet unknown sequence-independent factors may exist to retain, detain or reimport specific miRNAs in the nucleus, and they may also be cell-type specific.

Notwithstanding the lack of clarity regarding mechanisms of nuclear miRNA localization, numerous studies have demonstrated their enrichment and functions in myriad mammalian cell types [37-45]. The functions of these nuclear miRNAs include regulation of gene and long non-coding RNA expression [37, 38, 46], controlling the biogenesis of other miRNAs [41] and finetuning the expression of mRNA expression in the cytoplasm [43] (Fig. 1). Many of these functions are relevant to hemopoiesis and cancer as outlined in the following sections.

\section{Nuclear-localized miRNAs in hemopoietic cells}

Hemopoiesis is one of the first processes in which the functions of miRNAs were elucidated [47, 48]. Lineage commitment towards blood cell production begins with the hemopoietic stem cell escaping quiescence and the stepwise acquisition of specific myeloid or lymphoid identities $[49,50]$. The process involves gradual changes in the expression patterns of hundreds of proteins, including transcription factors $[49,50]$ and cell cycle regulators [51], many of which are direct or indirect targets of miRNAs.

More than a decade ago, three miRNAs, miR-181a, miR-223 and miR-142 were recognized as key players in myeloid and lymphoid cell differentiation [47]. miR-181a is preferentially expressed in the B-lineage, miR-223 in the myeloid lineage and mir-142 in both B and myeloid lineages [47]. Remarkably, enforced expression of miR181a led to a doubling of B cells while persistent expression of miR-223 or miR-142 increased the number of $\mathrm{T}$ cells by $30-40 \%$ [47]. Subsequently, miR-181a has also been found to be crucial for $\mathrm{T}$ cell development and function, modulating $\mathrm{T}$ cell receptor signalling, in part through its role in the downregulation of multiple phosphatases including SHP2, PTPN22, DUSP5 and DUSP6 [52]. Other confirmed targets of miR-181a include TCR, $C D 69$ and $B C L-2$, all of which are regulated during $\mathrm{T}$ cell development [53].

Given the substantial literature on the role of miRNAs in hemopoiesis, studies that determined the cellular localization of miRNAs in hemopoietic cells are relatively few. Most studies have focused on the canonical roles of miRNAs in the post-transcriptional regulation of genes involved in hemopoiesis. The best examples of 
nuclear miRNA functions have been reported in the context of granulopoiesis (Table 1).

The myeloid specific miRNA, miR-223, has been well characterized as playing an essential role in the control of granulopoiesis. In the cytoplasm of myeloid progenitors, miR-223 targets transcription factors MEF2C and NF1A that usually promote myeloid progenitor cell proliferation $[54,55]$. The inhibition of cell proliferation in myeloid progenitors coincides with their differentiation into granulocytes. Notably, miR-223 also targets seed sequences in the NF1A promoter to induce transcriptional gene silencing via recruitment of the polycomb repressive complex and a consequent increase in DNA methylation levels [42]. These data indicate that both nuclear and cytoplasmic miR-223 work synergistically to silence NF1A during granulopoiesis [42, 54].

Our group has recently reported the enrichment of miRNAs including miR-690, miR-706 and miR-709 in the nucleus of primary $\mathrm{Lin}^{-} \mathrm{Sca}^{+} \mathrm{Kit}^{+}$hemopoietic stem/ progenitor cells, promyelocytes, myelocytes and granulocytes [43]. We and others have also found miR-690 and/ or miR-709 to be nuclear-enriched in various human and mouse cell lines including MPRO, EL4, MEL, A20, L929 and HEK-293T indicating that their functions may be localized to the nucleus $[41,43]$. One of these miRNAs, miR-709, has been reported to bind with perfect complementarity to pri-miR-15a and pri-miR-16-1 and inhibit the biogenesis of these miRNAs [41]. This finding has established a previously unanticipated role of nuclear miRNAs in regulating or fine-tuning the expression of other miRNAs.

Our in silico analysis predicted many putative primary miRNA (pri-miRNA) sequences that could be targeted by miR-690, miR-706 or miR-709 with perfect complementarity [43]. Relevant to myelopoiesis, miR-706 is predicted to bind perfectly to a hemopoeitic-specific miR142-3p, which is known to play an essential role in granulocyte homeostasis and maturation $[43,56]$. Nevertheless, we were not able to demonstrate an increase of pri-miR-142-3p processing following inhibition of miR706 with a hairpin inhibitor against this miRNA [43]. Our result indicates the complexity of factors that determine miRNA binding to its targets in the nucleus, which are not likely to be dependent on sequences alone.

Importantly, we further reported that miRNAs may be retained in the nucleus to fine-tune the expression of mRNA targets [43]. For example, miR-706 enrichment in the nucleus is associated with decreased cytoplasmic miR-706 expression. Consequently, the expression of its targets such as the myeloid transcription factors, Stat1, increases to promote myeloid differentiation $[43,57]$.

\section{Nuclear-localized miRNAs in cancer}

The nuclear localization of miRNAs in cancer cells is well documented. Cancer cell lines including the 5-8F nasopharyngeal carcinoma cells, the HCT116 colorectal cancer cells and the THP-1 acute monocytic leukaemia cells harbor hundreds of miRNAs that are enriched in the nucleus of these cells $[28,29,58]$. The nuclearspecific functions of many of these miRNAs remain elusive, but they are likely to regulate or fine-tune the expression of cancer-associated genes. For example, miR10a, which is nuclear-localized in both the HCT116 and THP-1 cell lines $[29,58]$, has been reported to inhibit the transcription of Hoxd4 in the breast cancer cell lines, MCF7 and MDA-MB-231 [39]. Nuclear-localized miR10a binds with near perfect complementarity to the promoter of this tumor invasion and metastasis-promoting gene to trigger its silencing via hypermethylation and trimethylation of histone 3 lysine 27 at its promoter [39]. This example demonstrates that nuclear enrichment of miR-10a may provide a therapeutic opportunity to modulate gene expression relevant to cancer metastasis.

Table 1 Nuclear-localized miRNAs in normal hemopoiesis

\begin{tabular}{|c|c|c|c|c|}
\hline $\begin{array}{l}\text { Nuclear } \\
\text { miRNA }\end{array}$ & Lineage/cell type & Function/activity & Significance & Reference \\
\hline miR-223 & Myeloid & $\begin{array}{l}\text { Binds to the promoter region of } \\
N F 1 A \text { to induce transcriptional } \\
\text { silencing }\end{array}$ & $\begin{array}{l}\text { Repression of NF1A to promote } \\
\text { granulopoiesis }\end{array}$ & [42] \\
\hline miR-706 & $\begin{array}{l}\text { Myeloid ( } \mathrm{Lin}^{-} \mathrm{Sca}^{+} \mathrm{Kit}^{+} \text {hemopoietic stem/progenitor } \\
\text { cells, promyelocytes, myelocytes and granulocytes), } \\
\text { MPRO, EL4, MEL, A20 }\end{array}$ & $\begin{array}{l}\text { Detained in the nucleus to } \\
\text { derepress target mRNA (e.g. } \\
\text { Stat } 1 \text { ) }\end{array}$ & $\begin{array}{l}\text { Increased expression of transcription } \\
\text { factor (e.g. Stat1) to promote } \\
\text { granulopoiesis }\end{array}$ & {$[43,57]$} \\
\hline miR-690 & $\begin{array}{l}\text { Myeloid ( } \mathrm{Lin}^{-} \mathrm{Sca}^{+} \mathrm{Kit}^{+} \text {hemopoietic stem/progenitor } \\
\text { cells, promyelocytes, myelocytes and granulocytes), } \\
\text { MPRO, EL4, MEL, A2O }\end{array}$ & Unknown & Unknown & [43] \\
\hline miR-709 & $\begin{array}{l}\text { Myeloid ( } \mathrm{Lin}^{-} \mathrm{Sca}^{+} \mathrm{Kit}^{+} \text {hemopoietic stem/progenitor } \\
\text { cells, promyelocytes, myelocytes and granulocytes), } \\
\text { MPRO, EL4, MEL, A20 }\end{array}$ & Unknown & Unknown & [43] \\
\hline $\begin{array}{l}\text { miR- } \\
467 a^{*}\end{array}$ & $\begin{array}{l}\mathrm{Lin}^{-} \mathrm{Sca}^{+} \mathrm{Kit}^{+} \text {hemopoietic stem/progenitor cells, MPRO, } \\
\mathrm{EL} 4, \mathrm{~A} 20\end{array}$ & Unknown & Unknown & [43] \\
\hline
\end{tabular}


A

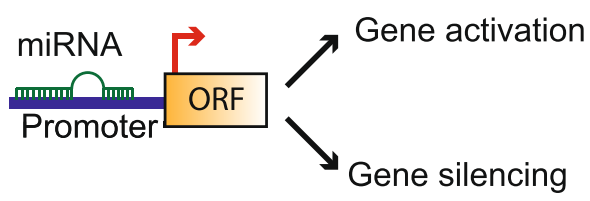

C

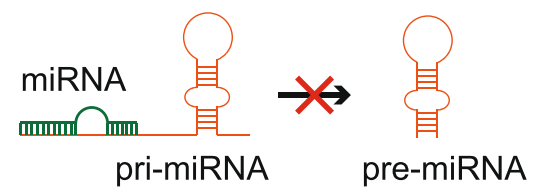

B
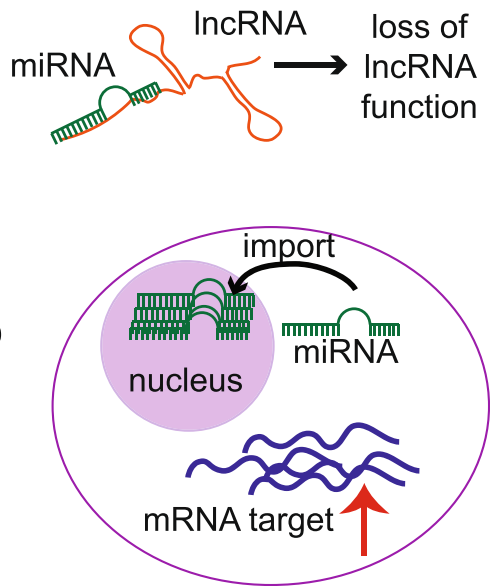

Fig. 1 Known roles of nuclear-localized miRNAs. a Regulation of gene expression by targeting gene promoters to activate or silence genes. $\mathbf{b}$ Targeting and suppressing long non-coding RNA (IncRNA) function. c Perturbation of miRNA biogenesis via binding to primary miRNA (pri-mRNA) transcripts. d Fine-tuning mRNA target expression through detention of miRNAs in the nucleus

Other nuclear-localized miRNAs have been reported to promote transcriptional activation of oncogenes by binding to their promoters. Examples include miR-483 that binds to the promoter of IGF2 to increase its expression in Wilms' tumors [59] and miR-558 that binds to the promoter of heparanase (HPSE) to enhance its expression, resulting in enhanced tumor growth in neuroblastoma cells [44] (Table 2).
Nuclear-localized miRNAs can also protect against tumorigenesis by promoting the activation of tumor suppressor genes. For example, miR-373 binds to the promoter of $\mathrm{CDH} 1$ to increase its expression in the prostate cancer cell line, PC3 [38]. miR-124 promotes the activation of $P 27$, leading to $G 1$ arrest in myriad breast and ovarian cancer cell lines [60]. miR-205 induces the expression of the interleukin tumor

Table 2 Function of nuclear-localized miRNAs relevant to human cancers

\begin{tabular}{|c|c|c|c|}
\hline $\begin{array}{l}\text { Nuclear } \\
\text { miRNA }\end{array}$ & Function & Cancer cells & Reference \\
\hline miR-10a & $\begin{array}{l}\text { Inhibit Hoxd4 to control cancer } \\
\text { metastasis }\end{array}$ & Breast cancer cell lines: MCF7 and MDA-MB-231 & [39] \\
\hline miR-483 & $\begin{array}{l}\text { Activate IGF2 to enhance } \\
\text { tumorigenesis }\end{array}$ & Wilms' tumors & [59] \\
\hline miR-558 & $\begin{array}{l}\text { Activate HPSE to promote tumor } \\
\text { growth }\end{array}$ & Neuroblastoma cell lines: SK-N-SH, SK-N-AS, SH-SY5Y and SK-N-BE(2) & [44] \\
\hline $\operatorname{miR}-373$ & $\begin{array}{l}\text { Increase expression of } \mathrm{CDH} 1 \text { tumor } \\
\text { suppressor gene }\end{array}$ & Prostate cancer cell line: PC3 & [38] \\
\hline miR-124 & $\begin{array}{l}\text { Activate tumor suppressor gene, } \\
\text { P27 }\end{array}$ & $\begin{array}{l}\text { Breast and ovarian cancer cell lines: MDA-MB-231, HeyA8, SKOV3.ip1, } \\
\text { SKBr3, OVCAR-3, } \\
\text { BxPC-3 and L3.6pl, MIA PaCa 2, Panc1, U87, SNB19 and LN229 }\end{array}$ & {$[60]$} \\
\hline miR-205 & $\begin{array}{l}\text { Activate interleukin tumor } \\
\text { suppressor genes, IL24 and IL32 }\end{array}$ & Prostate cancer cell lines: PC3, LNCaP and Du145 & [45]. \\
\hline miR-774 & Promote transcription of Ccnb1 & Mouse prostate adenocarcinoma cell line: TRAMP C1 & {$[61]$} \\
\hline $\operatorname{miR}-370$ & $\begin{array}{l}\text { Activate tumor suppressor gene, } \\
\text { P21 }\end{array}$ & Bladder cancer cell lines: T24 and EJ & [76] \\
\hline miR-1180 & $\begin{array}{l}\text { Activate tumor suppressor gene, } \\
\text { P21 }\end{array}$ & Bladder cancer cell lines: T24 and EJ & [76] \\
\hline miR-1236 & $\begin{array}{l}\text { Activate tumor suppressor gene, } \\
\text { P21 }\end{array}$ & Bladder cancer cell lines: T24 and EJ & [76] \\
\hline miR-939 & $\begin{array}{l}\text { Repression of } B C l-x l \text { anti-apoptosis } \\
\text { gene }\end{array}$ & Human neuroblastoma cell line: SH-SY5Y & [62] \\
\hline
\end{tabular}


suppressor genes, IL24 and IL32, by targeting specific regions of their promoters [45]. Additional examples are provided in Table 2.

The mechanisms by which binding of miRNAs to gene promoters results in transcriptional activation or silencing have also been described. They include increased or decreased levels of histone modifications associated with gene activation [39, 45, 61], altered RNA Polymerase II activity [38, 61], enhanced recruitment of transcription factors [59] and inhibition of transcription factor binding due to the presence of decoy miRNAs [62].

Besides coding genes, cancer-associated nuclear long non-coding RNAs (lncRNAs), MALAT-1 and XIST, have been reported as a target of miR-9 and miR-210, respectively $[63,64]$. The HOTAIR IncRNA, which localizes to both the nucleus and cytoplasm, has also been reported as a target of miR34a in prostate cancer cells [65]. However, it is unknown whether this interaction occurs in the nucleus. The GENCODE Consortium has mapped over 10,000 lncRNAs as putative miRNA targets, many of which are nuclear-enriched [66]. Further experimental validations will no doubt identify more nuclear lncRNAs as miRNA targets that are relevant to cancer.

Surprisingly, no report has previously reviewed the role of nuclear miRNAs in haematological malignancies despite the known roles of miRNAs as oncogenes or tumor suppressor genes $[18,67]$. miR-15a and miR-16-1 are established tumor suppressor miRNAs in chronic lymphocytic leukaemia. Their biogenesis is known to be regulated by the nuclear-localized miR-709 in liver cells $[41,67]$. Whether or not miR-709 fine-tunes the expression of miR-15a and miR-16 in chronic lymphocytic leukaemia remains to be determined. As described in the previous section of this review, nuclear miR-223 has a key role in normal granulopoiesis. A decrease in miR223 expression level is associated with CEBPA-mutated acute myeloid leukaemia [68]. Inhibition of the miR-223 target gene, E2F1, by CEBPA is pivotal to prevent leukemogenesis that results from E2F1-mediated expression of the oncogene tribble (Trib) 2 gene [68, 69]. As such both miR-223 and CEBPA regulate the expression of E2F1 in myeloid cells under normal physiological condition. Whether aberrant nuclear detention of miR-223 can occur to derepress E2F1 in CEBPA mutant leukaemia demands further investigation.

\section{Challenges in determining the functions of nuclear miRNAs}

The role of nuclear-localized miRNAs has been relatively neglected as evidenced by the extensive literature on miRNAs, including those relevant to hemopoiesis and cancer. Indeed, the majority of studies have focused on the action of miRNAs in post-transcriptional gene regulation. Several reports have considered miRNAs' role in transcriptional regulation of specific mRNAs only when these miRNAs did not act canonically via 3' UTR targeting [39, 61]. Others have focused on the transcriptional regulation of specific genes by miRNAs because these genes are known to be transcriptionally regulated by other synthetic or endogenous double-stranded small RNAs [37, 38]. In order to promote more rapid elucidation of the nuclear-associated roles of thousands of miRNAs, studies should specifically seek to identify nuclear miRNAs and their functions, notwithstanding the technical challenges.

Most studies reporting nuclear-localized miRNAs have utilized nuclear and cytoplasmic fractionation methods to determine their localization. Inevitably, the difficulty in obtaining a perfectly pure nuclear fraction has provoked scepticism concerning the accuracy of reported studies. Ensuring the removal of the cytoplasmic fraction prior to collection of the nuclear fraction is crucial and not always possible with some cells. It is also important to perform validations to show the absence of contaminating factors by western blot and RT-qPCR in conjunction with microscopy-based detection of nuclear miRNA labelled with fluorescence probes. These experimental procedures are laborious and often require cell-type specific optimizations to obtain reliable results. This is particularly relevant for commercially available nuclear and cytoplasmic extraction kits typically optimized for use with commonly studied cell lines such as HeLa. In our recent work, we undertook considerable optimization steps beyond the manufacturer's protocol to obtain good quality nuclear and cytoplasmic fractions from primary cells [43].

Upon identification of nuclear miRNAs, one next logical step is to determine where they bind. Bioinformatic tools have been developed to predict targets of miRNAs within gene promoters or pri-miRNAs [70, 71]. Nearly 800,000 miRNA seed sequences match over 27,000 promoter sequences [71]. miRNAs can also target gene promoters through non-seed related complementarity [45], indicating that miRNA binding to promoter regions may be more widespread than previously thought.

However, similar to the complexity of 3' UTR targeting by miRNAs, predicted miRNA-promoter/pri-miRNA pairing often did not result in the expected functional changes or occur in a cell-type specific manner $[38,43]$. Thus, cause-effect experiments are necessary to confirm that the binding of miRNAs to genomic sequences in the nucleus results in functional consequences.

Experiments designed to reduce the expression of miRNAs that localized specifically to the nucleus are technically challenging. Indeed, our recent report shows the dominant cytoplasmic localization of anti-miR-706 when transfected into myeloid cells [43]. In a study that reported the inhibition of miR-15a and miR-16 
processing by miR-709 in mouse L929 liver cells, modest upregulation of miR-15a and miR-16 $(<2$-fold) was detected in anti-miR-709 transfected cells [41]. It has not been shown whether anti-miR-709 entered the nucleus to inhibit miRNA processing. Thus, a direct role of nuclear miR-709 in controlling the expression of other miRNAs remains elusive.

A recent study has reported the utility of a snoRNAbased vector (snoVector) that allows efficient nuclear retention of RNA molecules processed from this vector [72]. RNA sequences such as lncRNAs, coding mRNAs and precursor miRNAs (pre-miRNAs) can be inserted into the snoVector. They can subsequently be processed into functional RNAs via the endogenous snoRNA processing machinery. RNA molecules expressed using snoVector have been reported to be nuclear-enriched, including those that are typically localized to the cytoplasm [72]. A similar vector (snoMEN) created via manipulation of the human C/D small nuclear RNA HBII$180 \mathrm{C}$ has also been reported to target nuclear RNA [73]. It has been utilized to express interfering RNAs that effectively reduced the expression of complementary sequences including nuclear pre-mRNA and pri-miRNA [74, 75]. Thus, it may be possible to use snoVector or SnoMEN to constrain anti-miRNA sequences to the nucleus. This step may facilitate functional characterization following specific and efficient repression of nuclear miRNAs.

Nonetheless, it is important to recognize that miRNAs have been reported to shuttle from the cytoplasm into the nucleus. So, even if repression of specific nuclear miRNAs is achieved, the observed functional loss may be due to the overall depletion of cytoplasmic miRNAs that are inhibited when they enter the nucleus. In such a case, it would be very challenging to discern the specific role of a given nuclear-localized miRNA. Optimal experiment design should exclude changes in cytoplasmic miRNA expression as a contributor to any phenotypic alteration. Alternatively, despite experimental hurdles, it is necessary to distinguish the function of any given nuclear miRNA from its cytoplasmic counterpart.

\section{Conclusions}

The importance of miRNAs in hemopoiesis and cancer through the post-transcriptional regulation of the expression of relevant genes has been well-established. In recent years, non-canonical roles for nuclear-localized miRNAs have been uncovered. While there is evidence that nuclear miRNAs regulate the transcription of specific genes in hemopoietic and cancer cells, these examples are relatively few in the context of the vast published literature on miRNAs in these cell types. In this review, we have described nuclear miRNAs that promote granulopoieis and those that enhance the expression of tumor suppressor genes and oncogenes. The roles of nuclear miRNAs in the vast majority of myeloid and lymphoid cells remain to be determined. Their roles in cancer, including post-transcriptional silencing of tumor suppressor genes, is as yet unreported. Therefore, examination of the functions of these nuclear miRNAs should prove to be a fruitful area for further research.

\section{Abbreviations \\ 3' UTR: 3' untranslated region; Ago: Argonaute; HPSE: Heparanase; IncRNAs: Long non-coding RNAs; miRNA: MicroRNA; mRNA Messenger RNA pre-miRNA: Precursor miRNA; pri-miRNA: Primary miRNA; RISC: RNA-induced silencing complex}

\section{Acknowledgements}

Not applicable.

\section{Funding}

JEJR and JJ-LW received funding from the National Health and Medical Research Council of Australia (Grant Nos. 1061906 to JEJR, 1080530 and 1128175 to JEJR and JJ-LW, and 1126306 to JJ-LW). JEJR is funded by the Cancer Council of NSW, Cure the Future and an anonymous foundation. JJLW holds a Fellowship from the Cancer Institute of NSW.

\section{Availability of data and materials}

Data sharing is not applicable to this article as no dataset was generated or analyzed in this review.

\section{Authors' contributions \\ JEJR and JJ-LW wrote the manuscript. Both authors read and approved the final manuscript.}

\section{Competing interests}

The authors declare that they have no competing interests.

\section{Consent for publication}

Not applicable.

Ethics approval and consent to participate

Not applicable.

\section{Author details}

'Gene \& Stem Cell Therapy Program, Centenary Institute, University of Sydney, Camperdown 2050, Australia. ${ }^{2}$ Sydney Medical School, University of Sydney, Camperdown, NSW 2050, Australia. ${ }^{3}$ Cell and Molecular Therapies, Royal Prince Alfred Hospital, Camperdown 2050, Australia. ${ }^{4}$ Gene Regulation in Cancer Laboratory, Centenary Institute, University of Sydney, Camperdown 2050, Australia. ${ }^{5}$ Locked Bag 6, Newtown, NSW 2042, Australia.

Received: 22 November 2016 Accepted: 12 December 2016 Published online: 05 January 2017

\section{References}

1. Naidu S, Magee P, Garofalo M. MiRNA-based therapeutic intervention of cancer. J Hematol Oncol. 2015:8:68.

2. Sanchez-Mejias A, Tay Y. Competing endogenous RNA networks: tying the essential knots for cancer biology and therapeutics. J Hematol Oncol. 2015;8:30.

3. Moyano M, Stefani G. piRNA involvement in genome stability and human cancer. J Hematol Oncol. 2015;8:38.

4. Tian X, Tian J, Tang X, Ma J, Wang S. Long non-coding RNAs in the regulation of myeloid cells. J Hematol Oncol. 2016;9:99.

5. Chen L-L. The biogenesis and emerging roles of circular RNAs. Nat Rev Mol Cell Biol. 2016;17:205-11.

6. Bueno M, Malumbres M. MicroRNAs and the cell cycle. BBA-Mol Basis Dis. 2011;1812:592-601.

7. Clancy JL, Patel HR, Hussein SMI, Tonge PD, Cloonan N, Corso AJ, Li M, Lee D-S, Shin J-Y, Wong JJL, Bailey CG, Benevento M, Munoz J, Chuah A, Wood D, Rasko JEJ, Heck AJR, Grimmond SM, Rogers IM, Seo J-S, Wells CA, Puri 
MC, Nagy A, Preiss T. Small RNA changes en route to distinct cellular states of induced pluripotency. Nat Commun. 2014;5:5522.

8. Ivey KN, Srivastava D. MicroRNAs as regulators of differentiation and cell fate decisions. Cell Stem Cell. 2010;7:36-41.

9. Leonardo TR, Schultheisz HL, Loring JF, Laurent LC. The functions of microRNAs in pluripotency and reprogramming. Nat Cell Biol. 2012;14:1114-21.

10. Lindsay MA. microRNAs and the immune response. Trends Immunol. 2008; 29:343-51.

11. Nukui M, Mori Y, Murphy EA. A human herpesvirus 6A-encoded microRNA: role in viral lytic replication. J Virol. 2015;89:2615-27.

12. Yan Q, Li W, Tang Q, Yao S, Lv Z, Feng N, Ma X, Bai Z, Zeng Y, Qin D, Lu C. Cellular microRNAs 498 and 320d regulate herpes simplex virus 1 induction of Kaposi's sarcoma-associated herpesvirus lytic replication by targeting RTA. PLoS ONE. 2013;8:e55832.

13. Quiat $\mathrm{D}$, Olson EN. MicroRNAs in cardiovascular disease: from pathogenesis to prevention and treatment. J Clin Invest. 2013;123:11-8.

14. Haramati S, Chapnik E, Sztainberg Y, Eilam R, Zwang R, Gershoni N, McGlinn E, Heiser PW, Wills A-M, Wirguin I, Rubin LL, Misawa H, Tabin CJ, Brown R, Chen A, Hornstein E. miRNA malfunction causes spinal motor neuron disease. Proc Natl Acad Sci U S A. 2010;107:13111-6.

15. Andersen HH, Duroux M, Gazerani P. MicroRNAs as modulators and biomarkers of inflammatory and neuropathic pain conditions. Neurobiol Dis. 2014:71:159-68.

16. Jinnin M. Recent progress in studies of miRNA and skin diseases. J Dermatol. 2015:42:551-8.

17. Szabo G, Bala S. MicroRNAs in liver disease. Nat Rev Gastroenterol Hepatol. 2013;10:542-52.

18. Gordon JEA, Wong JJL, Rasko JEJ. MicroRNAs in myeloid malignancies. Brit J Haematol. 2013;162:162-76.

19. Jansson MD, Lund AH. MicroRNA and cancer. Mol Oncol. 2012;6:590-610.

20. Lin S, Gregory RI. MicroRNA biogenesis pathways in cancer. Nat Rev Cancer. 2015:15:321-33.

21. Mourelatos Z, Dostie J, Paushkin S, Sharma A, Charroux B, Abel L, Rappsilber $J$, Mann M, Dreyfuss G. miRNPs: a novel class of ribonucleoproteins containing numerous microRNAs. Genes Dev. 2002;16:720-8.

22. Hammond SM, Boettcher S, Caudy AA, Kobayashi R, Hannon G. Argonaute2, a link between genetic and biochemical analyses of RNAi. Science. 2001:293:1146-50.

23. Ha M, Kim VN. Regulation of microRNA biogenesis. Nat Rev Mol Cell Biol. 2014;15:509-24.

24. Millar AA, Waterhouse PM. Plant and animal microRNAs: similarities and differences. Funct Integr Genomics. 2005;5:129-35.

25. Ling $\mathrm{H}$, Fabbri $\mathrm{M}$, Calin GA. MicroRNAs and other non-coding RNAs as targets for anticancer drug development. Nat Rev Drug Discov. 2013;12:847-65

26. Jin HY, Xiao C. MicroRNA mechanisms of action: what have we learned from mice? Front Genet. 2015:6:328.

27. Jonas $\mathrm{S}$, Izaurralde $\mathrm{E}$. Towards a molecular understanding of microRNAmediated gene silencing. Nat Rev Genet. 2015:16:421-33.

28. Liao J-Y, Ma L-M, Guo Y-H, Zhang Y-C, Zhou H, Shao P, Chen Y-Q, Qu L-H. Deep sequencing of human nuclear and cytoplasmic small RNAs reveals an unexpectedly complex subcellular distribution of miRNAs and tRNA $3^{\prime \prime}$ trailers. PLOS ONE. 2010:5:e10563.

29. Park CW, Zeng $Y$, Zhang $X$, Subramanian S, Steer CJ. Mature microRNAs identified in highly purified nuclei from HCT116 colon cancer cells. RNA Biol. 2010;7:606-14.

30. Nishi K, Nishi A, Nagasawa T, Ui-Tei K. Human TNRC6A is an Argonautenavigator protein for microRNA-mediated gene silencing in the nucleus. RNA. 2013;19:17-35.

31. Gagnon KT, Li L, Chu Y, Janowski BA, Corey DR. RNAi factors are present and active in human cell nuclei. Cell Rep. 2014;6:211-21.

32. Liang $\mathrm{H}$, Zhang J, Zen $\mathrm{K}$, Zhang $\mathrm{C}-\mathrm{Y}$, Chen $\mathrm{X}$. Nuclear microRNAs and their unconventional role in regulating non-coding RNAs. Protein Cell. 2013;4: $325-30$

33. Roberts TC. The microRNA biology of the mammalian nucleus. Mol Ther Nucleic Acids. 2014:3:e188.

34. Hwang H-W, Wentzel EA, Mendell JT. A hexanucleotide element directs microRNA nuclear import. Science. 2007:315:97-100.

35. Hwang H-W, Wentzel EA, Mendell JT. Nucleotide motifs providing localization elements and methods of use. Geneva: World Intellectual Property Organization. 2007. Patent No. WO 2007/149521 A2.
36. Jeffries CD, Fried HM, Perkins DO. Nuclear and cytoplasmic localization of neural stem cell microRNAs. RNA. 2011:17:675-86.

37. Kim DH, Sætrom P, Snøve O, Rossi JJ. MicroRNA-directed transcriptional gene silencing in mammalian cells. Proc Natl Acad Sci U S A. 2008;105: 16230-5.

38. Place RF, Li L-C, Pookot D, Noonan EJ, Dahiya R. MicroRNA-373 induces expression of genes with complementary promoter sequences. Proc Natl Acad Sci U S A. 2008;105:1608-13.

39. Tan Y, Zhang B, Wu T, Skogerbø G, Zhu X, Guo X, He S, Chen R. Transcriptional inhibiton of Hoxd4 expression by miRNA-10a in human breast cancer cells. BMC Mol Biol. 2009;10:12.

40. Younger ST, Corey DR. Transcriptional gene silencing in mammalian cells by miRNA mimics that target gene promoters. Nucleic Acids Res. 2011;39: 5682-91.

41. Tang R, Li L, Zhu D, Hou D, Cao T, Gu H, Zhang J, Chen J, Zhang C-Y, Zen K. Mouse miRNA-709 directly regulates miRNA-15a/16-1 biogenesis at the posttranscriptional level in the nucleus: evidence for a microRNA hierarchy system. Cell Res. 2011;22:504-15.

42. Zardo G, Ciolfi A, Vian L, Starnes LM, Billi M, Racanicchi S, Maresca C, Fazi F, Travaglini L, Noguera N, Mancini M, Nanni M, Cimino G, Lo-Coco F, Grignani F, Nervi C. Polycombs and microRNA-223 regulate human granulopoiesis by transcriptional control of target gene expression. Blood. 2012;119:4034-46.

43. Wong JJ, Ritchie W, Gao D, Lau KA, Gonzalez M, Choudhary A, Taft RJ, Rasko $J E$, Holst J. Identification of nuclear-enriched miRNAs during mouse granulopoiesis. J Hematol Oncol. 2014;7:42.

44. Qu H, Zheng L, Pu J, Mei H, Xiang X, Zhao X, Li D, Li S, Mao L, Huang K, Tong Q. miRNA-558 promotes tumorigenesis and aggressiveness of neuroblastoma cells through activating the transcription of heparanase. Hum Mol Genet. 2015;24:2539-51.

45. Majid S, Dar AA, Saini S, Yamamura S, Hirata H, Tanaka Y, Deng G, Dahiya R. MicroRNA-205-directed transcriptional activation of tumor suppressor genes in prostate cancer. Cancer. 2010;116:5637-49.

46. Hansen TB, Wiklund ED, Bramsen JB, Villadsen SB, Statham AL, Clark SJ, Kjems J. miRNA-dependent gene silencing involving Ago2-mediated cleavage of a circular antisense RNA. EMBO J. 2011;30:4414-22.

47. Chen C-Z, Li L, Lodish HF, Bartel DP. MicroRNAs modulate hematopoietic lineage differentiation. Science. 2004;303:83-6.

48. Garzon R, Croce CM. MicroRNAs in normal and malignant hematopoiesis. Curr Opin Hematol. 2008;15:352-8.

49. Rosenbauer F. Tenen DG. Transcription factors in myeloid development: balancing differentiation with transformation. Nat Rev Immunol. 2007:7:105-17.

50. Novershtern N, Subramanian A, Lawton LN, Mak RH, Haining WN, McConkey ME, Habib N, Yosef N, Chang CY, Shay T, Frampton GM, Drake ACB, Leskov I, Nilsson B, Preffer F, Dombkowski D, Evans JW, Liefeld T, Smutko JS, Chen J, Friedman N, Young RA, Golub TR, Regev A, Ebert BL. Densely interconnected transcriptional circuits control cell states in human hematopoiesis. Cell. 2011;144:296-309.

51. Passeguë E, Wagers AJ, Giuriato S, Anderson WC, Weissman IL. Global analysis of proliferation and cell cycle gene expression in the regulation of hematopoietic stem and progenitor cell fates. J Exp Med. 2005;202:1599-611.

52. Li Q-J, Chau J, Ebert PJR, Sylvester G, Min H, Liu G, Braich R, Manoharan M, Soutschek J, Skare P, Klein LO, Davis MM, Chen C-Z. miR-181a is an intrinsic modulator of T cell sensitivity and selection. Cell. 2007;129:147-61.

53. Neilson JR, Zheng GXY, Burge CB, Sharp PA. Dynamic regulation of miRNA expression in ordered stages of cellular development. Genes Dev. 2007;21: 578-89.

54. Fazi F, Rosa A, Fatica A, Gelmetti V, De Marchis ML, Nervi C, Bozzoni I. A minicircuitry comprised of microRNA-223 and transcription factors NFI-A and C/EBPa regulates human granulopoiesis. Cell. 2005;123:819-31.

55. Johnnidis JB, Harris MH, Wheeler RT, Stehling-Sun S, Lam MH, Kirak O, Brummelkamp TR, Fleming MD, Camargo FD. Regulation of progenitor cell proliferation and granulocyte function by microRNA-223. Nature. 2008;451: $1125-9$

56. Fan H-B, Liu Y-J, Wang L, Du T-T, Dong M, Gao L, Meng Z-Z, Jin Y, Chen Y, Deng $M$, Yang $H-T$, Jing Q, Gu A-H, Liu T-X, Zhou Y. miR-142-3p acts as an essential modulator of neutrophil development in zebrafish. Blood. 2014; 124:1320-30.

57. Hegde VL, Nagarkatti P, Nagarkatti M. MicroRNAs and their role in the generation of myeloid derived suppressor cells (MDSC) by cannabidiol in vivo. J Immunol. 2012;188:48.16. 
58. Taft RJ, Simons C, Nahkuri S, Oey H, Korbie DJ, Mercer TR, Holst J, Ritchie W, Wong JJL, Rasko JEJ, Rokhsar DS, Degnan BM, Mattick JS. Nuclear-localized tiny RNAs are associated with transcription initiation and splice sites in metazoans. Nat Struct Mol Biol. 2010;17:1030-4.

59. Liu M, Roth A, Yu M, Morris R, Bersani F, Rivera MN, Lu J, Shioda T, Vasudevan S, Ramaswamy S, Maheswaran S, Diederichs S, Haber DA. The IGF2 intronic miR-483 selectively enhances transcription from IGF2 fetal promoters and enhances tumorigenesis. Genes Dev. 2013;27:2543-8.

60. Seviour EG, Sehgal V, Lu Y, Luo Z, Moss T, Zhang F, Hill SM, Liu W, Maiti SN, Cooper L, Azencot R, Lopez-Berestein G, Rodriguez-Aguayo C, Roopaimoole R, Pecot C, Sood AK, Mukherjee S, Gray JW, Mills GB, Ram PT. Functional proteomics identifies miRNAs to target a p27/Myc/phospho-Rb signature in breast and ovarian cancer. Oncogene. 2016;35:691-701.

61. Huang V, Place RF, Portnoy V, Wang J, Qi Z, Jia Z, Yu A, Shuman M, Yu J, Li L-C. Upregulation of cyclin B1 by miRNA and its implications in cancer. Nucleic Acids Res. 2012:40:1695-707.

62. Cui C, Yu J, Huang S, Zhu H, Huang Z. Transcriptional regulation of gene expression by microRNAs as endogenous decoys of transcription factors. Cell Physiol Biochem. 2014;33:1698-714.

63. Leucci E, Patella F, Waage J, Holmstrøm K, Lindow M, Porse B, Kauppinen S, Lund AH. microRNA-9 targets the long non-coding RNA MALAT1 for degradation in the nucleus. Sci Rep. 2013;3:2535.

64. Fasanaro P, Greco S, Lorenzi M, Pescatori M, Brioschi M, Kulshreshtha R, Banfi C, Stubbs A, Calin GA, Ivan M, Capogrossi MC, Martelli F. An integrated approach for experimental target identification of hypoxia-induced miR-210 J Biol Chem. 2009;284:35134-43.

65. Chiyomaru T, Yamamura S, Fukuhara S, Yoshino H, Kinoshita T, Majid S, Saini S, Chang I, Tanaka Y, Enokida H, Seki N, Nakagawa M, Dahiya R. Genistein inhibits prostate cancer cell growth by targeting miR-34a and oncogenic HOTAIR. PLOS ONE. 2013;8:e70372.

66. Jeggari A, Marks DS, Larsson E. miRcode: a map of putative microRNA target sites in the long non-coding transcriptome. Bioinformatics. 2012;28:2062-3.

67. Fabbri M, Garzon R, Andreeff M, Kantarjian HM, Garcia-Manero G, Calin GA. MicroRNAs and noncoding RNAs in hematological malignancies: molecular, clinical and therapeutic implications. Leukemia. 2008;22:1095-105.

68. Pulikkan JA, Dengler V, Peramangalam PS, Peer Zada AA, Müller-Tidow C, Bohlander SK, Tenen DG, Behre G. Cell-cycle regulator E2F1 and microRNA223 comprise an autoregulatory negative feedback loop in acute myeloid leukemia. Blood. 2010;115:1768-78.

69. Rishi L, Hannon M, Salomè M, Hasemann M, Frank A-K, Campos J, Timoney J, O'Connor C, Cahill MR, Porse B, Keeshan K. Regulation of Trib2 by an E2F1-C/EBPa feedback loop in AML cell proliferation. Blood. 2014;123:2389-400.

70. Rehmsmeier M, Steffen P, Höchmann M, Giegerich R. Fast and effective prediction of microRNA/target duplexes. RNA. 2004;10:1507-17.

71. Younger ST, Pertsemlidis A, Corey DR. Predicting potential miRNA target sites within gene promoters. Bioorg Med Chem Lett. 2009;19:3791-4.

72. Yin Q-F, Hu S-B, Xu Y-F, Yang L, Carmichael GG, Chen L-L. SnoVectors for nuclear expression of RNA. Nucleic Acids Res. 2014;43:e5.

73. Ono M, Yamada K, Avolio F, Scott MS, van Koningsbruggen S, Barton GJ, Lamond Al. Analysis of human small nucleolar RNAs (snoRNA) and the development of snoRNA modulator of gene expression vectors. Mol Biol Cell. 2010;21:1569-84.

74. Ono M, Yamada K, Endo A, Avolio F, Lamond Al. Analysis of human protein replacement stable cell lines established using snoMEN-PR vector. PLoS ONE. 2013;8:e62305.

75. Ono M, Yamada K, Avolio F, Afzal V, Bensaddek D, Lamond Al. Targeted knock-down of miR21 primary transcripts using snoMEN vectors induces apoptosis in human cancer cell lines. PLoS ONE. 2015;10:e0138668.

76. Wang C, Chen Z, Ge Q, Hu J, Li F, Hu J, Xu H, Ye Z, Li L-C. Up-regulation of p21WAF1/CIP1 by miRNAs and its implications in bladder cancer cells. FEBS Lett. 2014;588:4654-64.

\section{Submit your next manuscript to BioMed Central and we will help you at every step:}

- We accept pre-submission inquiries

- Our selector tool helps you to find the most relevant journal

- We provide round the clock customer support

- Convenient online submission

- Thorough peer review

- Inclusion in PubMed and all major indexing services

- Maximum visibility for your research

Submit your manuscript at www.biomedcentral.com/submit

CBiomed Central 